\title{
Power Quality Improvement using Three Phase Unified Power Flow Controller (PI-Fuzzy-ANN)
}

\author{
G. Hemavathi, S. Sherine, Aarthisuriya
}

\begin{abstract}
Realities gadgets are utilized to control the power stream, to expand the transmission limit and to upgrade the strength of the power framework.. The controller utilized in the control instrument significantly affects controlling the power stream. As indicated by this, the capacity of UPFC is seen by utilizing distinctive control methodologies dependent on PI, fluffy rationale controllers (FLC) and fake neural system controllers in this investigation. Fluffy rationale controller is structured dependent on Mamdani's Fuzzy Inference Method while ANN depends on weighted normal method.This paper investigations the impact of controllers on execution of UPFC on the transmission lines that is liable to control quality aggravations, for example, waveform contortion and DC balance.
\end{abstract}

Keywords:Fuzzy Logic Controller

\section{INTRODUCTION}

The development of intensity frameworks in future depends significantly on expanding the ability of existing transmission frameworks as opposed to building new, ecological benevolent and affordable transmission lines and power stations. This powers the requirement for new control controllers that can productively build the transmission capacity and power stream control inside recommended limits. Also, these new controllers must have the option to control the voltage levels and the progression of the genuine/responsive power in the transmission line to utilize full capacity of the framework now and again with no decrease in the framework solidness and security edges. This prompted another innovation idea known as Flexible Alternating Current Transmission Systems (FACTS) innovation that was displayed in the late of 1980s. Realities gadgets upgrade the steadiness of the power framework with its quick control attributes and consistent repaying ability. Subsequently power stream control and expanding transmission capacity are the two principle targets of FACTS gadgets. Gyugyi proposed the Unified Power Flow Controller, which is the new kind age of FACTS gadgets in 1991[1]. Bound together Power Flow Controller (UPFC) is the individual from FACTS gadget that has developed for the

Revised Manuscript Received on August 22, 2019.

G.Hemavathi, Assistant Professor Department of EEE,Bharath Institute of Higher Education \& Research,TamilNAdu

S.Sherine, Assistant Professor Department of EEE,Bharath Institute of Higher Education \& Research,TamilNAdu

Aarthisuriya, Assistant Professor Department of EEE,Bharath Institute of Higher Education \& Research,TamilNAdu controlling and the streamlining of intensity stream in the electrical power transmission frameworks. This gadget shaped of the mix of two different FACTS gadgets to be specific as Static Synchronous Compensator (STATCOM) and the Static Synchronous Series Compensator (SSSC). These are associated with one another by a typical DC interface, which is a run of the mill stockpiling capacitor. The all parameters of the power transmission line (impedance, voltage and stage edge) can be control all the while. The control instrument and the controller essentially impact the introduction of UPFC. In the arrangement, two or three control instruments are utilized in UPFC models. Mamdani's comfortable deduction system is proposed and used to improve the dynamic control of true and responsive power. The power change is damped rapidly and the estimation of responsive power is compelled as conceivable by utilizing two or three time constants. At any rate there is no worth changed in the genuine power. The power change is damped speedily and the estimation of responsive power is compelled as conceivable by utilizing a few time constants. At any rate there is no worth changed in the confirmed power. The limit of UPFC on controlling of the power stream and the adequacy of controllers on execution of UPFC in the power transmission line are surveyed in two sensible assessments by utilizing unquestionable control portions dependent on PI and padded controllers in this paper.

\section{UPFC MODEL}

The Unified Power Flow Controller (UPFC) thought was proposed by Gyugyi in 1991[1].The UPFC was devised for the progressing control and dynamic compensation of ac transmission systems, giving multifunctional versatility required to deal with tremendous quantities of the issues standing up to the power movement industry. Inside the arrangement of standard power transmission thoughts, the UPFC can control, simultaneously or explicitly, all of the parameters affecting power stream in the transmission line (i.e., voltage, impedance, and stage point), and this unprecedented capacity is meant by the enlightening word "united" in its name. On the other hand, it can uninhibitedly control both the real and responsive power stream in the line. The peruser should audit that, for all of the Controllers discussed in the past parts, the control of certifiable power is connected with tantamount change in responsive power, i.e., extended authentic power stream moreover achieved extended open line control

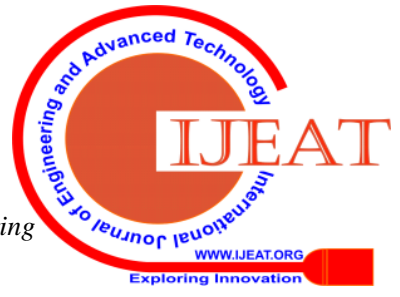




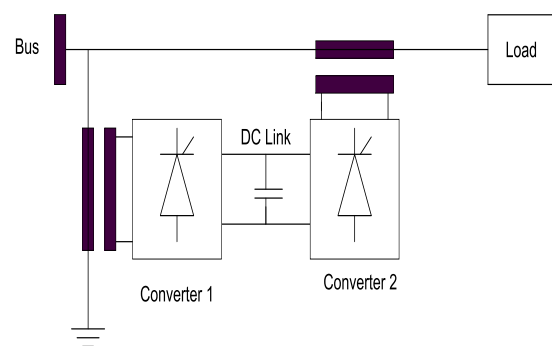

Fig.1 Basic model of UPFC

\section{Basic Operating Principles}

The essential capacity of Converter 1 is to supply or assimilate the genuine power demandedby Converter 2 at the normal de connect to help the genuine power trade resultingfrom the arrangement voltage infusion. This de connection power request of Converter 2 is changed over back to air conditioning by Converter 1 and coupled to the transmission line transport by means of a shuntconnected transformer. Notwithstanding the genuine power need of Converter 2,

\section{FUZZY LOGIC CONTROLLER}

The Fuzzy Logic instrument was presented in 1965, additionally by Lotfi Zadeh[2], and isa numerical device for managing vulnerability. It offers to a delicate computingpartnership the significant idea of figuring with words'. It furnishes atechnique to manage imprecision and data granularity. The fuzzytheory gives a component to speaking to etymological develops such as"many," "low," "medium," "frequently," "few." as a rule, the fluffy rationale providesan induction structure that empowers fitting human thinking capacities. [1],[3],[5]

Despite what might be expected, the customary parallel set hypothesis depicts fresh occasions, eventsthat either do or don't happen. It utilizes likelihood hypothesis to clarify if anevent will happen, estimating the opportunity with which a given occasion is expectedto happen. The hypothesis of fluffy rationale depends on the thought of relative gradedmembership as are the elements of mentation and subjective processes. The utility of fluffy sets lies in their capacity to show unsure or equivocal information.

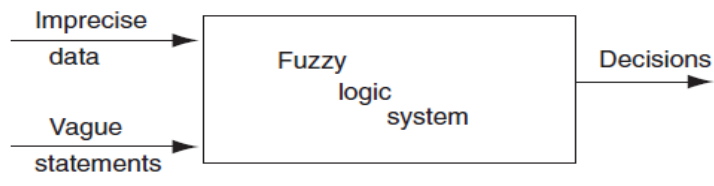

Fig.2 Basic implementation of Fuzzy Logic

Essential six stages to be pursued while utilizing a fluffy rationale controller:

1. Determining a set of fuzzy rules

2. Fuzzifying the inputs using the input membership functions

3. Combining the fuzzified inputs according to the fuzzy rules to establish a rule strength

4. Finding the consequence of the rule by combining the rule strength andthe output membership function

5. Combining the consequences to get an output distribution

6. Defuzzifying the output distribution

Inference method requires a fuzzy rule table. The rule table used in our paper is as shown in Table. 1.

\begin{tabular}{|c|c|c|c|c|c|c|c|}
\hline $\begin{array}{c}\text { ERROR } \\
\text { IERROR }\end{array}$ & NB & NM & NS & ZP & PS & PM & PB \\
\hline NB & PB & PB & PB & PB & PM & PM & PS \\
\hline NM & PB & PM & PM & PM & PS & PS & PS \\
\hline NS & PM & PM & PS & PS & PS & PS & ZO \\
\hline ZO & NS & NS & NS & ZO & PS & PS & PS \\
\hline PS & ZO & NS & NS & ZO & PS & PS & PS \\
\hline PM & NS & NS & NM & NM & NM & NB & NB \\
\hline PB & NS & NM & NB & NB & NB & NB & NB \\
\hline
\end{tabular}

Table 1 Fuzzy Rule Table

Centroid strategy:

This is the most broadly utilized strategy. This can be called as focal point of gravity or focus of region strategy. It very well may be characterized by the arithmetical articulation

$$
z^{*}=\int \frac{\mu \underset{\sim}{c}(z) z d z}{\mu \underset{\sim}{c}(z) d z}
$$

\section{ARTIFICIAL NEURAL NETWORK CONTROLLER}

A first wave of enthusiasm for neural networks(also known as connectionist models or parallel distributed processing) rose after the presentation of simplified neurons by McCulloch and Pitts (1943)[4].

The fundamental handling components of neural networks are called artificial neurons, or just neurons or hubs. In a simplified numerical model of the neuron, the effects of the neurotransmitters are spoken to by association loads that modulate the impact of the related info signals, and the nonlinear trademark displayed by neurons is represented by an exchange work. The neuron drive is then computed as the weighted whole of the info signals, changed by the move work. The learning ability of an artificial neuron is accomplished by altering the loads in accordance to the picked learning algorithm. The essential engineering comprises of three kinds of neuron layers: input, covered up, and yield layers. In feed-forward networks, the sign flow is from contribution to yield units, strictly in a feed-forward direction. The information processing can reach out over various (layers of) units, yet no criticism associations are present. A neural system must be configured with the end goal that the application of a lot of sources of info creates the ideal set of outputs. Different strategies to set the qualities of the associations exist. One route is to set the loads unequivocally, using a priori information. Another route is to prepare the neural system by sustaining it showing examples and letting it change its loads as indicated by some learning guideline[2 ], [ 4],[6] 


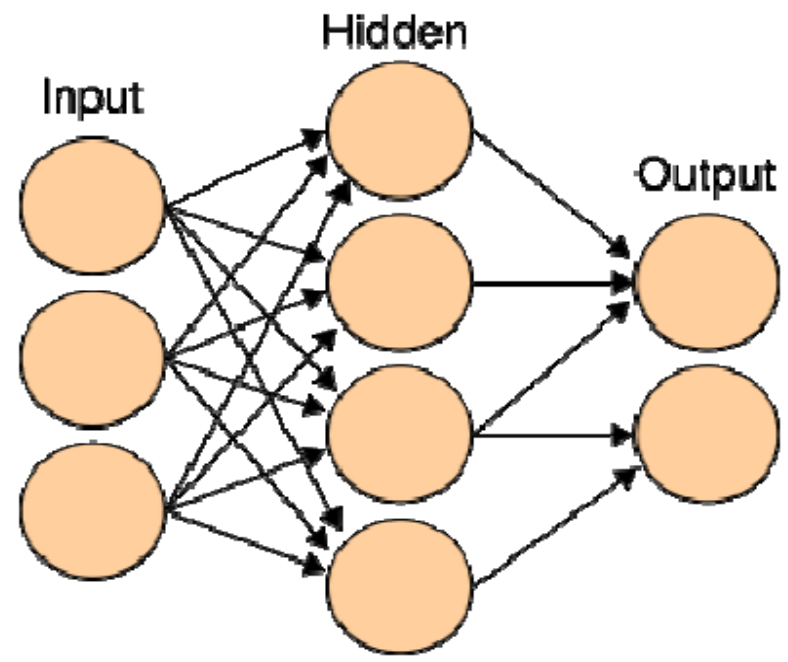

Fig.3Simple Neural Network Model

\section{SIMULATION RESULTS}

For our research, we have designed a 14-bus system with Non Linear Load and observed the waveform distortion and Total Harmonic Distortion (THD \%). The UPFC with various controllers was incorporated to analyze improvement and compared. (Refer- Fig. 4-11 and Table 2) [7],[ 9] ,[11]

Another analysis for presence of DC, i.e. DC offset was done and results were compared. DC offset was simulated using a Universal bridge Rectifier Load.

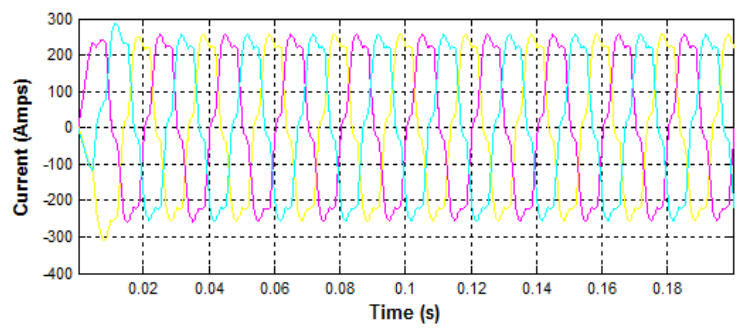

Fig. 4 Without UPFC

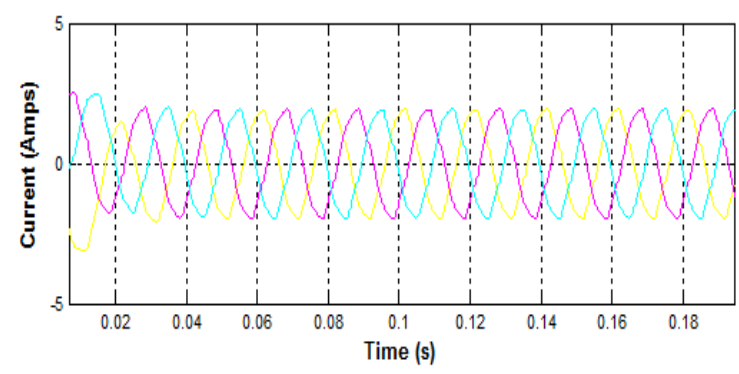

Fig. 5 UPFCwith PI Controller:

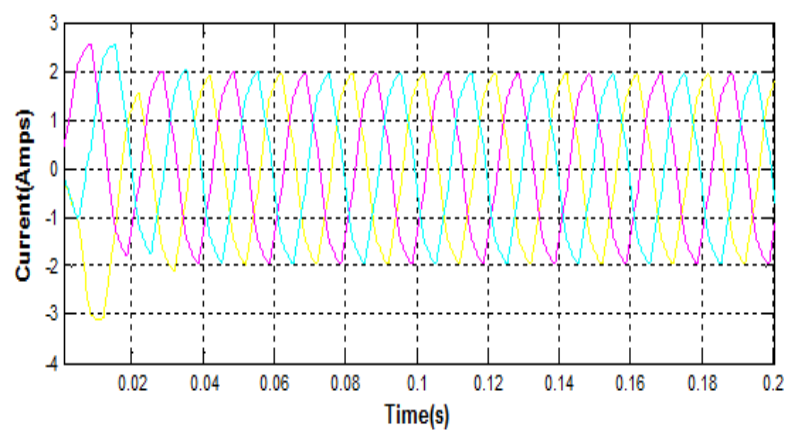

Fig. 6 UPFC with Fuzzy Controller:

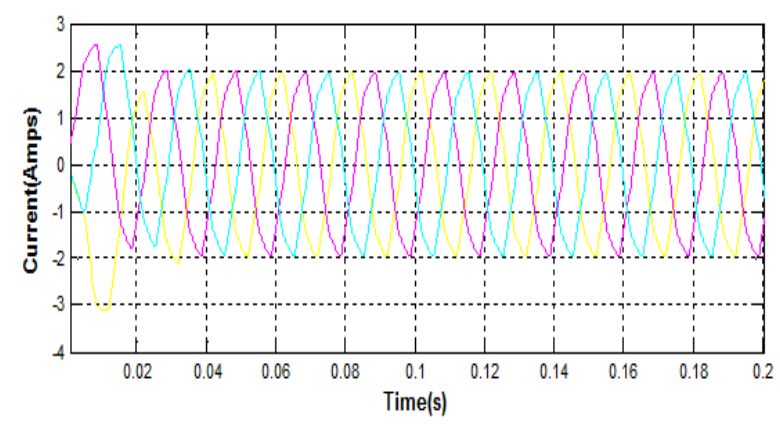

Fig. 7 UPFC with ANN Controller:

$$
\frac{\sqrt{\sum_{n=2}^{\infty} V_{n}^{2}}}{V_{1}}
$$

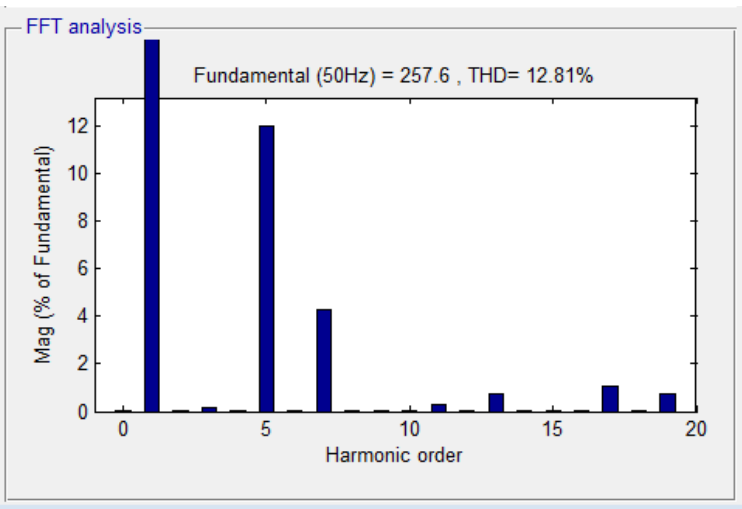

Fig. 8 FFT Analysis - without UPFC connected

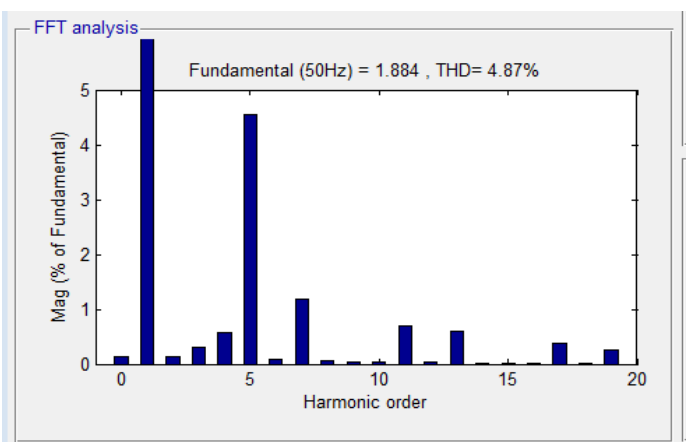

Fig. 9 FFT Analysis - UPFC with PI controller connected

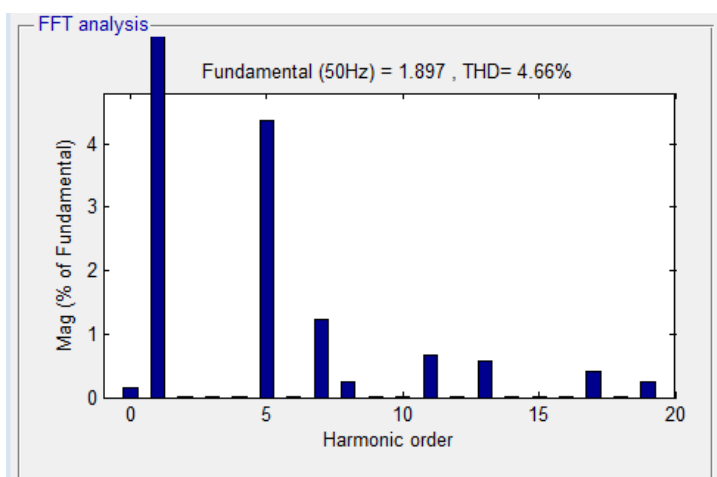

Fig. 10 FFT Analysis - UPFC with Fuzzy Controller connected

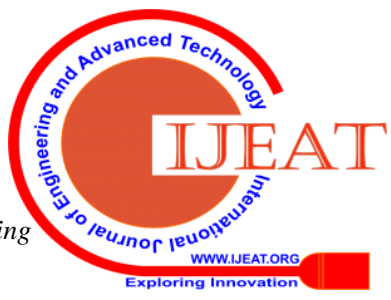




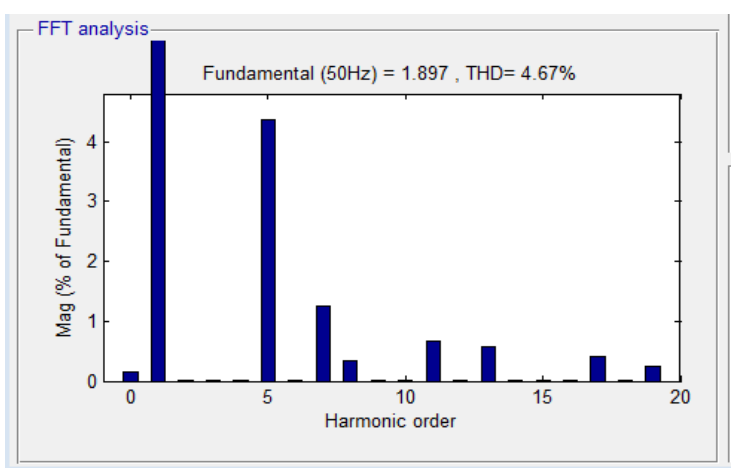

Fig. 11 FFT Analysis - UPFC with ANN controller connected

Table 2. THD COMPARISON TABLE

\begin{tabular}{|c|c|}
\hline & THD (\%) \\
\hline WITHOUT UPFC & 12.81 \\
\hline UPFC WITH PI & 4.87 \\
\hline UPFC WITH FUZZY & 4.66 \\
\hline UPFC WITH ANN & 4.67 \\
\hline
\end{tabular}

It is evident from the above plots that the waveform distortion present when no UPFC is connected in the system is considerably reduced subsequently in the system with UPFC connected. With UPFC incorporated in the system corresponding THD \% is improved and is within IEEE 519 Standard. Of the 3 controllers Fuzzy Controller proves the best in containing waveform distortion and limiting the THD $\%$.

Simulating a bridge rectifier load in the system generates DC offset in the system and the results are as follows:

DC Offset: The presence of DC components in AC waveform.

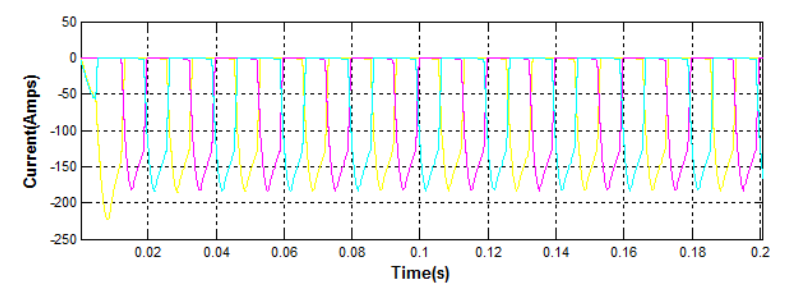

Fig. 12 Without UPFC

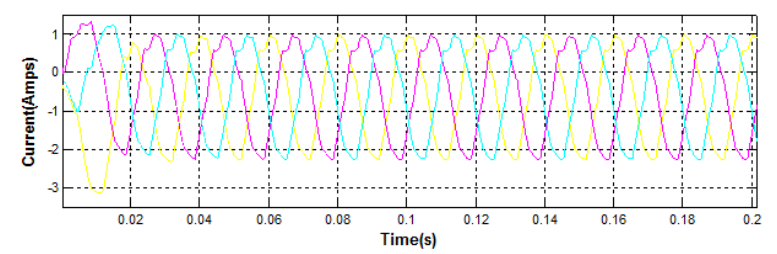

Fig. 13 UPFC with PI Controller

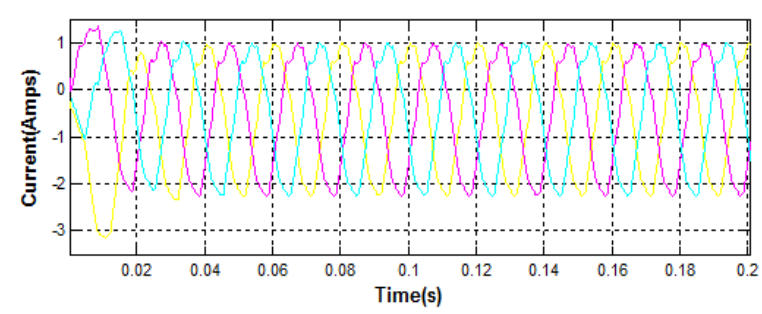

UPFC with Fuzzy

Controller

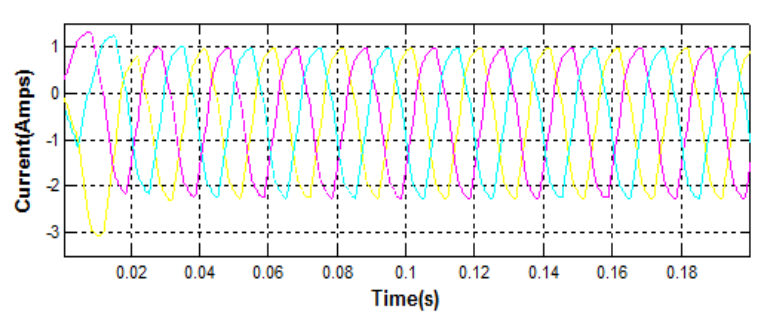

Fig. 15 UPFC with ANN controller

The system without a UPFC connected has a high level of DC offset. The introduction of UPFC greatly enhances the quality of output by counteracting the DC offset. It is evident from Fig 13-15 that, of the three controllers ANN proves the best in reducing the DC components in the system effectively. [14],[16], [18]

\section{CONCLUSION}

Through this paper we provide a comparison under different controlling strategies such as PI, Fuzzy and ANN. Through the use of UPFC, we enhance power quality of the system by mitigating the effects of waveform distortion, harmonics and DC offset. [19],[21],

\section{REFERENCES}

1. Kongkham, D. \& Sundararajan, M. 2019, "Distributed wideband sensing method for faded dynamic spectrum access", International Journal of Innovative Technology and Exploring Engineering, vol. 8, no. 10 , pp. 4309-4312.

2. Balaji, S., John Paul Praveen, A. \& Mohanraj, R. 2019, "Recognizable proof and analysis of palm print in biometric authentication system using bayes techniques", International Journal of Innovative Technology and Exploring Engineering, vol. 8, no. 9 Special Issue 3, pp. 1126-1129.

3. Kavitha, G., Priya, N., Velvizhi, R. \& Allin Geo, A.V. 2019, "Parallel computation in correspondence and signal processing", International Journal of Innovative Technology and Exploring Engineering, vol. 8, no. 9 Special Issue 3, pp. 1136-1139.

4. Hema, R., Sundararajan, M. \& Balaji, S. 2019, "Smartphone control robot with automatic firing gun", International Journal of Innovative Technology and Exploring Engineering, vol. 8, no. 9 Special Issue 3, pp. 625-627.

5. Kaliyamurthie, K.P., Sundar Raj, B., Velvizhi, R. \& Shanmugapriya, K. 2019, "Dual band paper substrate CPW antenna for wireless applications", International Journal of Innovative Technology and Exploring Engineering, vol. 8, no. 9 Special Issue 3, pp. 605-608.

6. Geo, A.V.A., Arunachalam, A.R., Michael, G. \& Elankavi, R. 2019, "Evaluating architecture using compact modalities", International Journal of Innovative Technology and Exploring Engineering, vol. 8, no. 9 Special Issue 3, pp. 836-838.

7. Theivasigamani, S., Jeyapriya, D. \& Anita Davamani, K. 2019, "Anamoly analyzing and exploring for wireless sensor networks", International Journal of Innovative Technology and Exploring Engineering, vol. 8, no. 9 Special Issue 3, pp. 1116-1118.

8. Jeyapriya, D., Theivasigamani, S., Velvizhi, R. \& Nandhini, P. 2019, "Program detection in wireless feeler networks", International Journal of Innovative Technology and Exploring Engineering, vol. 8, no. 9 Special Issue 3, pp. 1194-1195.

9. Gowri Sankaran, B., Karthik, B. \& Vijayaragavan, S.P. 2019, "Image compression utilizing wavelet transform", International Journal of Innovative Technology and Exploring Engineering, vol. 8, no. 10, pp. 4305-4308.

10. Gowri Sankaran, B., Karthik, B. \& Vijayaragavan, S.P. 2019, "Weight ward change region plummeting

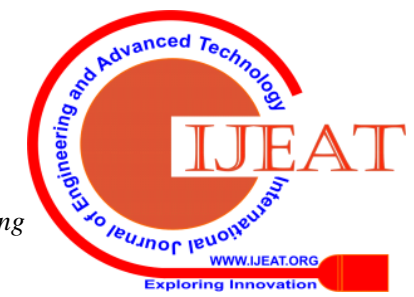


change for square based image huffman coding", International Journal of Innovative Technology and Exploring Engineering, vol. 8, no. 10, pp. 4313-4316.

11. Hema, R., Sundararajan, M. \& Balaji, S. 2019, "Smartphone control robot with automatic firing gun", International Journal of Innovative Technology and Exploring Engineering, vol. 8, no. 9 Special Issue 3, pp. 625-627.

12. Rangaswamy, K. \& Rajabhushanam, C. 2019, "Congestion control in wireless network using TCP friendly rate control (TFRC)", International Journal of Recent Technology and Engineering, vol. 8, no. 2 Special issue 3, pp. 1598-1602.

13. Tamil Selvan, S. \& Sundararajan, M. 2019, "Performance Parameters of 3 Value $8 \mathrm{t}$ Cntfet Based Sram Cell Design Using H-Spice", International Journal of Recent Technology and Engineering, vol. 8, no. 2 Special issue 5, pp. 22-27.

14. Vinoth, V.V. \& Kanniga, E. 2019, "Steganographical techniques in hiding text images - system", International Journal of Recent Technology and Engineering, vol. 8, no. 2, pp. 6535-6537.

15. Saravana, S., Balaji, S., Arulselvi, S. \& John Paul Praveen, A. 2019, "Reliable power quality monitoring and protection system", International Journal of Innovative Technology and Exploring Engineering, vol. 8, no. 9 Special Issue 3, pp. 644-645.

16. Sundaramoorthy, A. \& John Wiselin, M.C. 2019, "Single patch antenna with multiple feed", International Journal of Innovative Technology and Exploring Engineering, vol. 8, no. 9, pp. 1743-1747.

17. Velavan, R., Bharanidharan, S. \& Sheeba, B. 2019, "EMF pollution Causes, effects and protection", International Journal of Innovative Technology and Exploring Engineering, vol. 8, no. 9 Special Issue 3, pp. 1166-1168.

18. Veer, R.A., Arulselvi, S. \& Karthik, B. 2019, "Construction of ensemble square classification approaches in MIMO OFDM", International Journal of Engineering and Advanced Technology, vol. 8, no. 5, pp. 2039-2041.

19. Agitha, W. \& Kaliyamurthie, K.P. 2019, "Improved energy efficient in WBAN using MAC with cloud computing", International Journal of Innovative Technology and Exploring Engineering, vol. 8, no. 8, pp. 2405-2408.

20. Kastro, G.G. \& Wiselin, M.C.J. 2019, "Design and analysis of stub loaded resonator", International Journal of Recent Technology and Engineering, vol. 8, no. 1 Special Issue4, pp. 272-283.

\section{AUTHORS PROFILE}

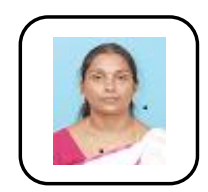

G.Hemavathi Assistant Professor Department of EEE,Bharath Institute of Higher Education \& Research,TamilNAdu

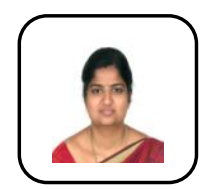

S.Sherine Assistant Professor Department of EEE,Bharath Institute of Higher Education \& Research,TamilNAdu

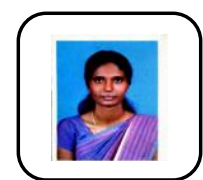

Aarthisuriya Assistant Professor Department of EEE,Bharath Institute of Higher Education \& Research,TamilNAdu 